\title{
Adjacent Segment Pathology after Anterior Cervical Fusion
}

\author{
Jae Yoon Chung ${ }^{1}$, Jong-Beom Park ${ }^{2}$, Hyoung-Yeon Seo ${ }^{1}$, Sung Kyu Kim ${ }^{1}$ \\ ${ }^{1}$ Department of Orthopedic Surgery, Chonnam National University Hospital, Chonnam National University Medical School, Gwangju, Korea \\ ${ }^{2}$ Department of Orthopaedic Surgery, Uijeongbu St. Mary's Hospital, College of Medicine, The Catholic University of Korea, Seoul, Korea
}

\begin{abstract}
Anterior cervical fusion has become a standard of care for numerous pathologic conditions of the cervical spine. However, subsequent development of clinically significant disc disease at levels adjacent to fused discs is a serious long-term complication of this procedure. As more patients live longer after surgery, it is foreseeable that adjacent segment pathology (ASP) will develop in increasing numbers of patients. Also, ASP has been studied more intensively with the recent popularity of motion preservation technologies like total disc arthroplasty. The true nature and scope of ASP remains poorly understood. The etiology of ASP is most likely multifactorial. Various factors including altered biomechanical stresses, surgical disruption of soft tissue and the natural history of cervical disc disease contribute to the development of ASP. General factors associated with disc degeneration including gender, age, smoking and sports may play a role in the development of ASP. Postoperative sagittal alignment and type of surgery are also considered potential causes of ASP. Therefore, a spine surgeon must be particularly careful to avoid unnecessary disruption of the musculoligamentous structures, reduced risk of direct injury to the disc during dissection and maintain a safe margin between the plate edge and adjacent vertebrae during anterior cervical fusion.
\end{abstract}

Keywords: Cervical vertebrae/surgery; Spinal fusion; Complications; Adjacent segment pathology; Risk factors; Reoperation

\section{Introduction}

Anterior cervical discectomy and fusion (ACDF) was first reported in 1955 [1]. This technique provide relatively easy access to surgical sites, a lower bleeding risk, and a good view of the operative field $[2,3]$. Over the past 60 years, ACDF has become a standard method for many pathologic conditions of the cervical spine. Anterior cervical fusion in conjunction with decompression provides relief of radicular complaints and improvement of myelopathic findings in over $90 \%$ of cases [1,4]. However, subsequent development of clinically significant disc disease at levels adjacent to fused discs is a serious longterm complication of this procedure (Fig. 1) [5,6]. Also, as more patients live longer after surgery, it is foreseeable that adjacent segment pathology (ASP) will develop in increasing numbers of patients. ASP has become a common topic in spine surgery because of the development of motion preservation technologies like total disc arthroplasty that theoretically should lead to a decrease in this pathology. With the recent popularity of this new motion preservation technology, the study of ASP has increased enormously.

However, controversy remains as to whether these

\footnotetext{
Received Sep 30, 2015; Accepted Oct 22, 2015

Corresponding author: Sung Kyu Kim

Department of Orthopedics, Chonnam National University Hospital, Chonnam National University Medical School, 42 Jebong-ro, Dong-gu, Gwangju 61469, Korea

Tel: +82-62-227-1640, Fax: +82-62-225-7794, E-mail: bonjourksk@hanmail.net
} 

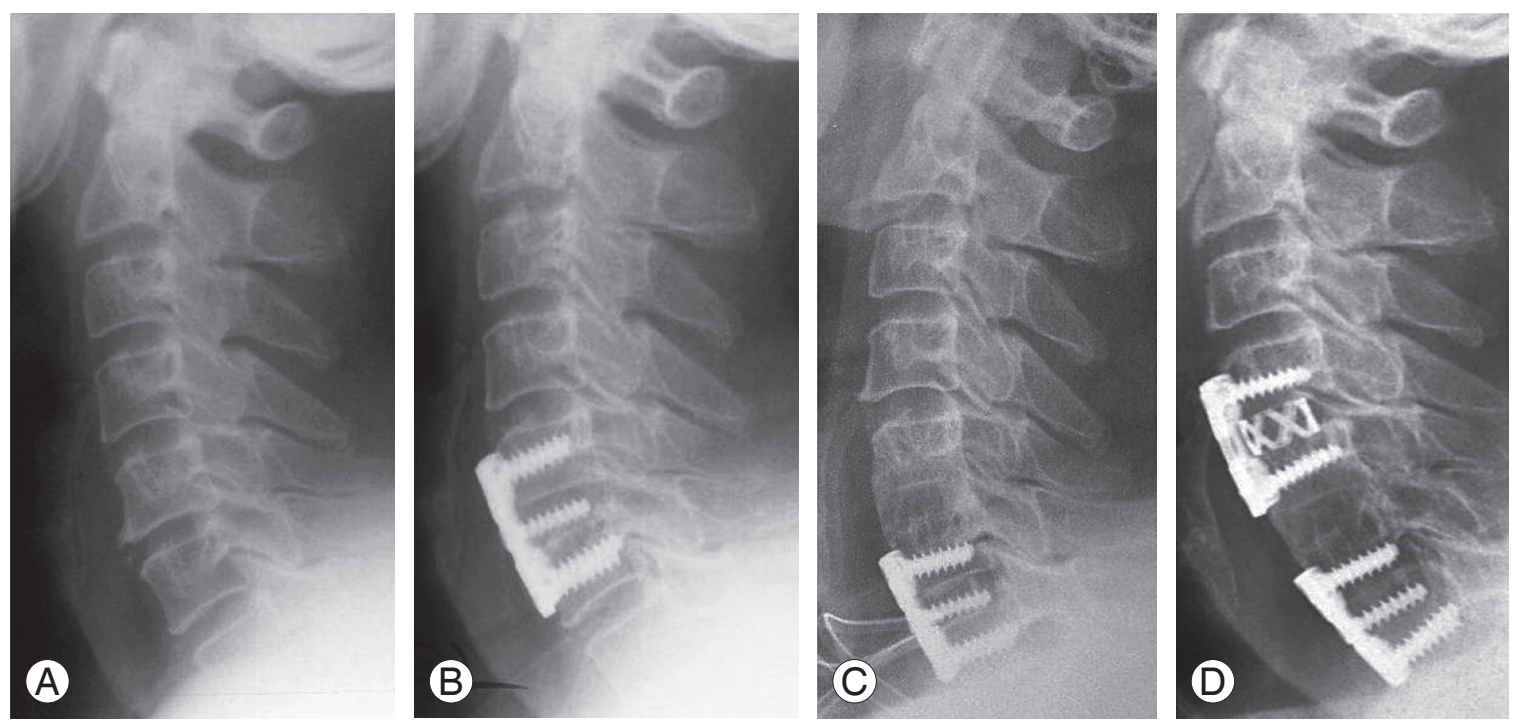

Fig. 1. Plain radiographs of a 57-year-old man. (A) Lateral imaging shows C5-6 spondylosis. (B) The patient had anterior fusion of C5-6. (C) After 2 years, he had anterior fusion of C6-7 due to disc herniation. (D) Anterior fusion of C4-5 due to cervical spondylosis was performed 9 years after the primary surgery.

conditions are related to altered biomechanics [5,7-11] or represent the natural history of cervical spondylosis at the adjacent segment [12-14]. Clearly, patients who have undergone cervical fusions are at an increased risk of developing ASP. What remains unknown is how much of this risk is related to the surgical procedure and the natural history of their disease.

This review presents data on the incidence, pathogenesis and clinical impact of ASP after cervical fusion, and summarizes the analyses of predictive factors and prevention of ASP. Many comparative studies associated with total disc arthroplasty have been reported. However, a comprehensive summary is beyond the scope of the present review.

\section{Terminology}

The true incidence and clinical impact of degenerative changes at the adjacent segment is unclear because of the lack of a universally accepted classification system that rigorously addresses clinical and radiological issues.

In the scientific literature, "adjacent segment degeneration", "adjacent segment disease”, "ASD”, "junctional disease", "junctional problem" and "junctional stenosis" have been used to describe spinal degenerative pathology, which coexists in the adjacent spine after a previous spinal fusion. "Degeneration" has also been poorly defined, and may separately refer to osteophyte formation, interverte- bral disc degeneration, spinal stenosis, segmental instability, facet arthrosis or significant structural deformity including kyphosis and scoliosis. Thus, although "ASD" is a commonly used term, its definition is imprecise and it is created varied and ambiguous literature regarding this pathology [15]. Recently, the term "adjacent segment degeneration" has been used to describe radiographic changes seen at levels adjacent to a previous spinal fusion that do not necessarily correlate with any clinical findings. On the other hand, the term "adjacent segment disease" has been used to refer to the development of new clinical symptoms that correspond to radiographic changes adjacent to the level of a previous spinal fusion. Despite the clear distinction between these two terms, they are also often used interchangeably in the literature.

A recent Spine Focus issue recommended uniform terminology comprising radiographic adjacent segment pathology without symptoms (RASP) and clinical adjacent segment pathology with symptoms (CASP). The term adjacent segment pathology (ASP) was proposed as an umbrella term to refer to the breadth of clinical and/or radiographical changes at adjacent motion segments that developed subsequent to a previous spinal fusion. Under this umbrella, RASP and CASP are then used to categorize radiographical features and clinical manifestations, respectively. The intent is to have a uniform and unambiguous terminology. 


\section{Pathogenesis}

Development of ASP following anterior cervical fusion has been amply described in the literature [5,12,16-23]. The cause of this degenerative process has been extensively studied in biomechanical studies using animal and cadaver models [24-27]. Still, the true nature and scope of ASP remains poorly understood. Whether ASP following ACDF represents a true iatrogenic postoperative complication or a progression of the natural history of cervical spondylosis remains unclear. The etiology of ASP is most likely multifactorial. No study has proven that a single risk factor directly correlates with this pathology. The natural history of degeneration, changes in intradiscal pressure, anatomy disruption and sagittal malalignment have been proposed as etiologic factors [28-30].

Many studies have focused on the altered biomechanics at the adjacent levels after fusion that result in increased mobility $[5,7,9,10]$, increased loading [8] or increased intradiscal pressure [11] that ultimately accelerate disc degeneration [25,31-33]. Increased mechanical demands adversely affect the disc by interfering with its normal nutritional supply. Impaired disc nutrition is the most significant cause of disc degeneration [31]. Increased pressure within the disc is believed to inhibit diffusion of nutrients, which leads to the accumulation of waste products [34]. Cadaveric studies of the spine have demonstrated that changes in pressure, force, and motion occur at adjacent levels as a result of arthrodesis $[24,35]$. Although these studies do not account for the true in vivo properties of living tissues and the contribution of the spinal musculature, they provide some insight into the altered forces at the adjacent segment after a fusion.

In a study that involved humans and animals, the authors reported that the mobile segments adjacent to the fusion segment showed an increased range of motion, and this effect is increased with multilevel fusions [36]. Another study reported that regardless of the fusion method, cervical fusion increased the mobility of the adjacent segments and facilitated degenerative change [37]. Also, at 7.2 years of follow-up monitoring, $32 \%$ of patients had recurrent pain and $16 \%$ required additional surgery.

Reported rates of ASP in patients with fusion seem to be higher than the rates of de novo degeneration in patients without fusion, suggesting that the fusion itself may have a contributory effect in the development of ASP.

Whereas some authors advocate the hypothesis of al- tered biomechanics, others focus on natural progression at adjacent levels after fusion. In addition, the aforementioned disc changes occurred during the normal aging process. As the disc ages, its nutrition is impaired because the presence of fewer peripheral arteries and of calcification of the cartilage end plates reduces the vascular supply. Furthermore, loss of viable cells, modification of matrix proteins and fatigue failure of the matrix occur [34]. Physiologic aging of the cervical spine has been observed in several cross-sectional and longitudinal studies in healthy volunteers. Magnetic resonance imaging (MRI) in 63 asymptomatic volunteers revealed that the intervertebral disc was narrowed or had degenerated at one or more cervical levels in $25 \%$ of those under 40 years of age and in $60 \%$ of those older than 40 years of age [38]. MRI of the cervical intervertebral discs of 497 asymptomatic subjects demonstrated a linear increase in degenerative findings with age, from $17 \%$ of men and $12 \%$ of women aged 20 to 29 years compared with $86 \%$ of men and $89 \%$ of women aged $>60$ years [39].

Fusion and nonfusion procedures have been compared to determine whether the fusion itself might be causative in the development of ASP. If the biomechanical consequences of cervical fusion were the only factor in the development of ASP, nonfusion procedures like anterior discectomy and posterior foraminotomy would not increase the risk. In a relatively short follow-up of $>1$ years involving 253 patients who underwent anterior cervical discectomy with fusion or discectomy alone, the authors did not find any difference in the rate of CASP between patients who underwent discectomy with fusion and those who underwent discectomy alone [40]. A retrospective review of a cohort of 846 patients after posterior foraminotomy without fusion with an average follow-up of 2.8 years reported 79 patients required additional procedures for CASP (9\%; approximate annual incidence, 3\%) [41]. A prospective study reported that after anterior cervical fusion, $41 \%$ of the patients had radiographic evidence of ASP at an average 4.5-year follow-up, compared with $50 \%$ of those who underwent posterior cervical laminoforaminotomy [42]. These clinical observations suggest that anterior decompression with fusion and posterior decompression without fusion may lead to similar rates of ASP.

The relationship between the number of the fused segments and ASP is contentious. Some studies have demonstrated an increased risk of degeneration with increasing length of fusion [43-46], while other studies reported 
that the increase in the number of fused segments did not result in a higher rate of ASP $[47,48]$. In one study, the risk of CASP after multilevel fusion was significantly less than after single-level fusion [12]. These findings are contrary with the results expected if the biomechanical consequences of fusion were the only cause of ASP. In recent years, total disc arthroplasty has become an alternate surgical procedure that may replace spinal fusion in patients with degenerative disc disease. The goals of disc arthroplasty are to preserve motion and restore the intervertebral disc and foraminal height to prevent recurrence of nerve root compression. But, after a 2- to 4-year followup, ASP was also found in total disc arthroplasty patients [49]. Therefore, whether ASP is caused by the natural progression of aging or by increased motion stress related to biomechanical factors secondary to the surgical fusion itself remains debatable.

Moreover, general factors linked with disc degeneration including gender, smoking and sporting activities may play a role in the development of ASP. Soft tissue disruption is also considered a potential cause of ASP, although this is much more difficult to experimentally elucidate. Surgical damage to the anterior longitudinal ligament or to the longus colli muscles can contribute to ASP. Incor- rect needle placement during intraoperative radiographiclevel confirmation was reported to increase the relative risk of developing ASP by three-fold [50]. The authors attributed the increased ASP to both the dissection over the adjacent level and the puncture of the annulus.

Considering the collective data, we think that various factors including altered biomechanical stresses, surgical disruption of soft tissue and the natural history of cervical disc disease are causal for the development of ASP (Fig. 2).

\section{Clinical ASP and Reoperation}

ASP has been reported in multiple studies after both anterior and posterior fusions, and at single and multilevel. However, the reported incidence has varied. At an average 100.6 month follow-up, $92 \%$ of the 180 patients treated by ACDF demonstrated additional radiographic degeneration at the adjacent disc levels [51]. Another study reported that $92 \%$ of 177 patients treated by ACDF showed some degree of radiographic change [52]. Still another study reported RASP in $67 \%$ of participants after a mean follow-up of 27 months after anterior cervical fusion [7].

In contrast with previous studies about radiographic changes of adjacent level after cervical fusion, present
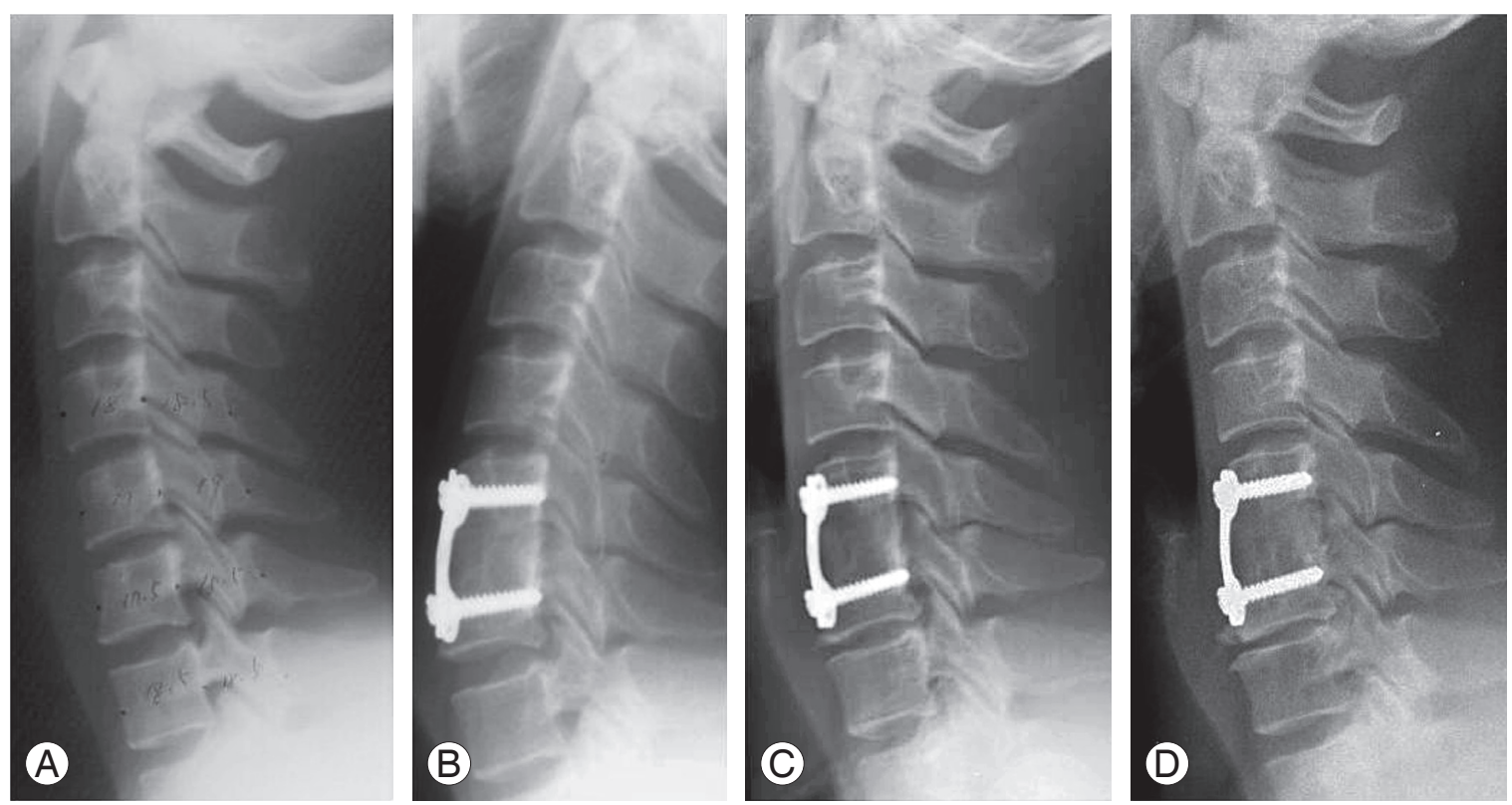

Fig. 2. Plain radiographs of a 43-year-old man. (A) Preoperative radiograph and (B) radiograph obtained immediately after C5-6 anterior fusion shows no degenerative change in the superior and inferior adjacent segments. (C) Radiograph obtained 16 years after surgery shows no change in the superior adjacent segments and mild degenerative changes in the inferior adjacent segments. The patient had no symptoms. (D) Radiograph obtained 21 years after surgery shows no change in the superior adjacent segments and moderate degenerative changes in the inferior adjacent segments. The patient had mild posterior neck pain and left arm radiating pain. But, symptom was controlled conservatively. 
studies focused on CASP. Hilibrand et al. [12] reported that new CASP occurred at a rate of $2.9 \%$ per year and that $25.6 \%$ would have new disease at an adjacent level within 10 years after ACDF. A review of the outcomes of 177 patients after ACDF found that 19.2\% developed CASP during a minimum 10 years of follow-up, of which $6.8 \%$ required reoperation [52]. Others observed new spondylosis in $25 \%$ of 121 patients and progression of preexisting spondylosis in another $25 \%$ of patients who had previously undergone anterior cervical fusion with an average follow-up of 5 years [53].

The incidence of cervical RASP has ranged widely from $18.33 \%$ [54] to $96 \%$ [37], as has CASP, with values from $11.1 \%$ [55] to $38.1 \%$ [7]. RASP occurs at a significantly higher rate than CASP, a finding clearly supported by the studies reviewed [20,22,51,54,56-61]. The relationship between RASP and CASP has been considered, specifically whether RASP can predict the development of CASP. No correlation between RASP and the development of clinical symptoms referable to radiographic changes has been apparent $[7,51,60]$. Consequently, radiographic evidence of degeneration of disc spaces adjacent to the site of anterior cervical fusion may be meaningful only when it is associated with clinical symptoms of radiculopathy or myelopathy referable to that level.

Varying rates of surgery to repair ASP have been reported. Several studies reported similar rates of $6 \%$ [51], $6.3 \%$ [18], 6.7\% [55] and 6.8\% [52], while higher rates of 9.1\% [13], 16\% [37] and 17\% [22,62] have been documented on other studies. When the number of years of follow-up is divided into the overall prevalence, the annual incidence of CASP requiring additional surgery is between $0.8 \%$ and $4 \%$ (Table 1 ).

Risk factors for follow-up surgery include type of surgery, smoking and female sex. In one study, the posterior arthrodesis group had a 7.5-times greater risk of ASP requiring follow-up surgery than those receiving posterior decompression, and a 3.0-times greater risk than the anterior arthrodesis group [63]. Possible causes included soft-tissue injury of ligaments, facet capsule and muscle during posterior arthrodesis, or the rigidity of posterior instrumentation.

\section{Plate-To-Disc Distance and Adjacent Level Ossification}

Anterior osteophyte formation is more frequently ob- served in those with fusion than in those without fusion. Fusion with cervical plates has been used widely in settings including trauma, disc herniation, spondylosis and tumors because of advantages that include initial stability, higher fusion rate, recovery of normal lordosis and the lack of necessity for external support. However, in patients with an anterior cervical plate, the distance between the plate and adjacent segments may influence the osteophyte at adjacent segments [64]. The association between adjacent level ossification and disease has not been proven, but the placement of the plate closer to the adjacent level could potentially disrupt the adjacent level anatomy, such as the anterior longitudinal ligament.

Some study reported that a plate-to-disc distance of less than $5 \mathrm{~mm}$ results in moderate or severe ossification of the adjacent segments and therefore a surgeon performing ACDF should try to achieve a distance of $5 \mathrm{~mm}$ or more $[64,65]$. Another study reported that most CASP occurred when the plate-to-disc distance was less than $5 \mathrm{~mm}$. Goffin et al. [51] also recommended using the shortest plate possible to avoid intrusion of the plate into the adjacent segments. A cutoff of $3 \mathrm{~mm}$ has been suggested to avoid adjacent level ossification development (ALOD) [66]. ALOD results in heterotopic bone formation along the anterior longitudinal ligament at the adjacent levels. In theory, ALOD may be caused by an inflammatory reaction between the plate and anterior longitudinal ligament leading to ossification. This is evidenced by higher rates of ALOD seen in plated ACDF compared with noninstrumented ACDF $[64,67,68]$.

ALOD is a sequela of a close plate and may also result from dissection at the disc. The closer the plate lies to the disc, the greater the risk of soft tissue dissection at the anulus, such as a soft tissue injury by a periosteal elevator or other surgical tool used when placing the cervical plates. This can lead to subsequent ossification. But, the precise mechanism of ALOD is still unknown.

Recently, other authors $[69,70]$ reported that although both ALOD and ASP can result in bone formation, the pathological mechanism of ALOD differs from that of osteophytic growth in ASP. They reported that patients with ALOD typically have better preservation of disc height compared with patients with ASP. Because ALOD in its severest stages causes ankylosis and a decrease in motion, the result is a "relative protection" of the adjacent level from degenerative changes. Patients with ASP are more likely to have disc protrusions, facet arthrosis, 

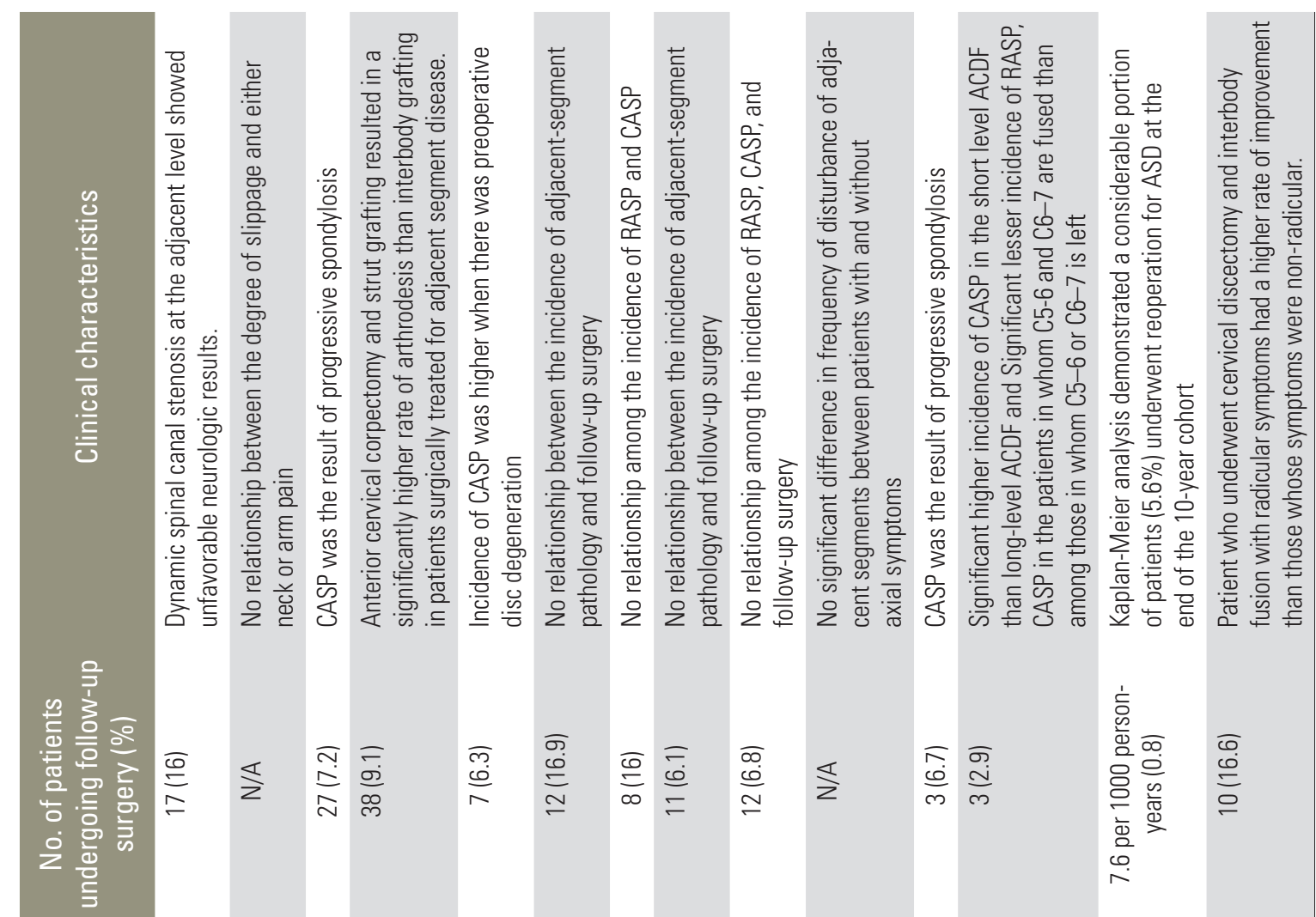

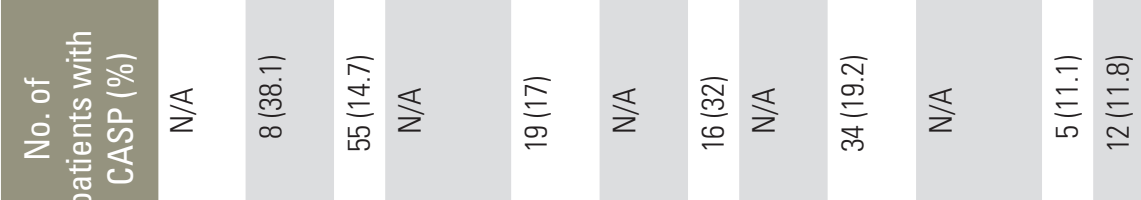

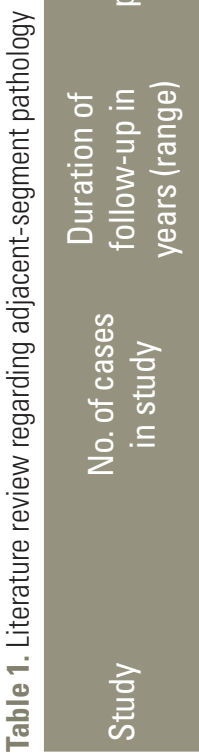

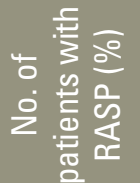

$\sqrt{\frac{1}{2}}$

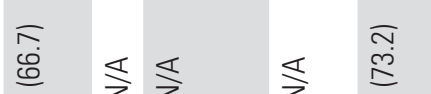

बृ

$=$

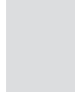


spondylolisthesis, endplate sclerosis and/or osteophyte formation. Also, the base of ALOD is situated anterior to the vertebral body, covering about half of it. However, the osteophytes seen in ASP are located anteroinferiorly in the vertebral body, covering no more than one-third of the body. It is not clear whether ASP is due to surgery or the natural history of degenerative disease. ALOD, on the contrary, seems to be an iatrogenic problem that has a high likelihood of developing if the plate is placed too close to the adjacent segment. More importantly, ALOD matures within the first 2 years after surgery, unlike in ASP, in which osteophytic bone and disc degeneration gradually increases over time $[12,65,68]$.

\section{Sagittal Malalignment}

ASP is multifactorial. Preoperative sagittal alignment and range of motion did not significantly affect ASP in a midterm follow-up evaluation after anterior fusion in degenerative cervical spinal disorders [71]. However, the sagittal alignment of the cervical spine after ACDF has been implicated in the progression of ASP with kyphotic sagittal segmental alignment being associated with a greater risk for radiologic and clinical degenerations $[54,72,73]$.

The effect of postoperative malalignment of the cervical spine was studied prospectively over 9.8 years; $43 \%$ of patients with ASP had malalignment of the cervical spine [60]. The authors reported that the kyphotic alignment of the cervical spine plays a major role in the degenerative changes of adjacent segments. After the fusion, the decreased lordotic angle causes abnormal stress distribution to the adjacent segments, and kyphosis generates increased tension in the posterior column during flexion and extension, resulting in the degeneration of the adjacent segments [74].

Malalignment after cervical arthrodesis promotes RASP at levels adjacent to the fused segment [73]. The retrospective study of 107 patients with one-level ACDF documented RASP in $27 \%$ of cases fused in lordosis and $60 \%$ of cases with fused in kyphosis, but no relationship was discernible between the overall cervical spine alignment and RASP. Others reported that malalignment of the cervical spine following an anterior fusion has an effect on the development of CASP requiring surgery [75]. The risk factors for CASP include preexisting degeneration at the adjacent levels, previous cervical fusion and sagittal cervical malalignment $[12,60,73]$.

\section{Prevention}

Although most cases of ASP may be unavoidable, some of these postoperative changes might be technique dependent. Incorrect needle placement during intraoperative radiographic-level confirmation was reported to increase the relative risk of developing ASP by three-fold [50]. The plate-to-disc distance is important, with separation by $<5$ $\mathrm{mm}$ driving the development of moderate or severe ossification of the adjacent segments $[64,65]$. Both of these studies highlight the importance of avoiding the soft tissue injury at the adjacent level. The disc has a poor capacity for regeneration and any significant injury will likely result in accelerated degeneration. Therefore, a spine surgeon must be particularly careful to discreet decision of the operative range through careful preoperative assessments, minimal exposure of the operation field, use of a short anterior cervical plate, decrease of surrounding soft tissue damage like anterior longitudinal ligament, needle placement in vertebral body during intraoperative radiographic-level confirmation and preservation of lordosis due to plate bending and delicate wedging of bone grafts during anterior cervical fusion.

\section{Conclusions}

Anterior cervical fusion is the preferred surgical procedure for symptomatic cervical spinal disease and cervical spondylosis. However, ASP after fusion is a common effect of this procedure and highly morbid condition, but remains a poorly understood. Surgeons should avoid unnecessary disruption of the musculoligamentous structures along the anterior vertebral border, reduce the risk of direct injury to the disc during dissection and maintain a safe margin between the plate edge and adjacent vertebrae. Various and continuous researches will improve the quality of clinical data on ASP and elucidate the true etiology and incidence of this condition.

\section{Conflict of Interest}

No potential conflict of interest relevant to this article was reported.

\section{References}

1. Robinson RA, Smith GW. Anterolateral cervical disc 
removal and interbody fusion for cervical disc syndrome. Bull John Hopkins Hosp 1955;96:223-4.

2. Connolly PJ, Esses SI, Kostuik JP. Anterior cervical fusion: outcome analysis of patients fused with and without anterior cervical plates. J Spinal Disord 1996; 9:202-6.

3. Suh PB, Kostuik JP, Esses SI. Anterior cervical plate fixation with the titanium hollow screw plate system: a preliminary report. Spine (Phila Pa 1976) 1990;15: 1079-81.

4. Bohlman HH, Emery SE, Goodfellow DB, Jones PK. Robinson anterior cervical discectomy and arthrodesis for cervical radiculopathy: long-term follow-up of one hundred and twenty-two patients. J Bone Joint Surg Am 1993;75:1298-307.

5. Baba H, Furusawa N, Imura S, Kawahara N, Tsuchiya $\mathrm{H}$, Tomita $\mathrm{K}$. Late radiographic findings after anterior cervical fusion for spondylotic myeloradiculopathy. Spine (Phila Pa 1976) 1993;18:2167-73.

6. Goffin J, van Loon J, Van Calenbergh F, Plets C. Long-term results after anterior cervical fusion and osteosynthetic stabilization for fractures and/ or dislocations of the cervical spine. J Spinal Disord 1995;8:500-8.

7. Dohler JR, Kahn MR, Hughes SP. Instability of the cervical spine after anterior interbody fusion: a study on its incidence and clinical significance in $21 \mathrm{pa}-$ tients. Arch Orthop Trauma Surg 1985;104:247-50.

8. Matsunaga S, Kabayama S, Yamamoto T, Yone K, Sakou T, Nakanishi K. Strain on intervertebral discs after anterior cervical decompression and fusion. Spine (Phila Pa 1976) 1999;24:670-5.

9. Woesner ME, Mitts MG. The evaluation of cervical spine motion below C2: a comparison of cineroentgenographic and conventional roentgenographic methods. Am J Roentgenol Radium Ther Nucl Med 1972;115:148-54.

10. Clements DH, O'Leary PF. Anterior cervical discectomy and fusion. Spine (Phila Pa 1976) 1990;15:10235.

11. Pospiech J, Stolke D, Wilke HJ, Claes LE. Intradiscal pressure recordings in the cervical spine. Neurosurgery 1999;44:379-84.

12. Hilibrand AS, Carlson GD, Palumbo MA, Jones PK, Bohlman HH. Radiculopathy and myelopathy at segments adjacent to the site of a previous anterior cervical arthrodesis. J Bone Joint Surg Am 1999;81:519-
28.

13. Hilibrand AS, Yoo JU, Carlson GD, Bohlman HH. The success of anterior cervical arthrodesis adjacent to a previous fusion. Spine (Phila Pa 1976) 1997;22: 1574-9.

14. Green PW. Anterior cervical fusion: a review of thirty-three patients with cervical disc degeneration. J Bone Joint Surg Br 1977;59:236-40.

15. Kraemer P, Fehlings MG, Hashimoto R, et al. A systematic review of definitions and classification systems of adjacent segment pathology. Spine (Phila $\mathrm{Pa}$ 1976) 2012;37(22 Suppl):S31-9.

16. Coric D, Nunley PD, Guyer RD, et al. Prospective, randomized, multicenter study of cervical arthroplasty: 269 patients from the Kineflex $\mid \mathrm{C}$ artificial disc investigational device exemption study with a minimum 2-year follow-up: clinical article. J Neurosurg Spine 2011;15:348-58.

17. Hunter LY, Braunstein EM, Bailey RW. Radiographic changes following anterior cervical fusion. Spine (Phila Pa 1976) 1980;5:399-401.

18. Ishihara $H$, Kanamori M, Kawaguchi $Y$, Nakamura $\mathrm{H}$, Kimura T. Adjacent segment disease after anterior cervical interbody fusion. Spine J 2004;4:624-8.

19. Kulkarni V, Rajshekhar V, Raghuram L. Accelerated spondylotic changes adjacent to the fused segment following central cervical corpectomy: magnetic resonance imaging study evidence. J Neurosurg 2004; 100(1 Suppl Spine):2-6.

20. Matsumoto M, Okada E, Ichihara D, et al. Anterior cervical decompression and fusion accelerates adjacent segment degeneration: comparison with asymptomatic volunteers in a ten-year magnetic resonance imaging follow-up study. Spine (Phila Pa 1976) 2010; 35:36-43.

21. Robertson JT, Papadopoulos SM, Traynelis VC. Assessment of adjacent-segment disease in patients treated with cervical fusion or arthroplasty: a prospective 2-year study. J Neurosurg Spine 2005;3:41723.

22. Yue WM, Brodner W, Highland TR. Long-term results after anterior cervical discectomy and fusion with allograft and plating: a 5- to 11-year radiologic and clinical follow-up study. Spine (Phila Pa 1976) 2005;30:2138-44.

23. Jawahar A, Nunley P. Total disc arthroplasty and anterior cervical discectomy and fusion in cervical 
spine: competitive or complimentary? Review of the literature. Global Spine J 2012;2:183-6.

24. Eck JC, Humphreys SC, Lim TH, et al. Biomechanical study on the effect of cervical spine fusion on adjacent-level intradiscal pressure and segmental motion. Spine (Phila Pa 1976) 2002;27:2431-4.

25. Maiman DJ, Kumaresan S, Yoganandan N, Pintar FA. Biomechanical effect of anterior cervical spine fusion on adjacent segments. Biomed Mater Eng 1999;9:2738.

26. Lopez-Espina CG, Amirouche F, Havalad V. Multilevel cervical fusion and its effect on disc degeneration and osteophyte formation. Spine (Phila Pa 1976) 2006;31:972-8.

27. Cole TC, Burkhardt D, Ghosh P, Ryan M, Taylor T. Effects of spinal fusion on the proteoglycans of the canine intervertebral disc. J Orthop Res 1985;3:27791.

28. Chang UK, Kim DH, Lee MC, Willenberg R, Kim $\mathrm{SH}$, Lim J. Changes in adjacent-level disc pressure and facet joint force after cervical arthroplasty compared with cervical discectomy and fusion. J Neurosurg Spine 2007;7:33-9.

29. Finn MA, Brodke DS, Daubs M, Patel A, Bachus KN. Local and global subaxial cervical spine biomechanics after single-level fusion or cervical arthroplasty. Eur Spine J 2009;18:1520-7.

30. Anakwenze OA, Auerbach JD, Milby AH, Lonner BS, Balderston RA. Sagittal cervical alignment after cervical disc arthroplasty and anterior cervical discectomy and fusion: results of a prospective, randomized, controlled trial. Spine (Phila Pa 1976) 2009;34:20017.

31. Buckwalter JA. Aging and degeneration of the human intervertebral disc. Spine (Phila Pa 1976) 1995;20: 1307-14.

32. Schwab JS, Diangelo DJ, Foley KT. Motion compensation associated with single-level cervical fusion: where does the lost motion go? Spine (Phila Pa 1976) 2006:31:2439-48.

33. Ragab AA, Escarcega AJ, Zdeblick TA. A quantitative analysis of strain at adjacent segments after segmental immobilization of the cervical spine. J Spinal Disord Tech 2006;19:407-10.

34. Rihn JA, Lawrence J, Gates C, Harris E, Hilibrand AS. Adjacent segment disease after cervical spine fusion. Instr Course Lect 2009;58:747-56.
35. Fuller DA, Kirkpatrick JS, Emery SE, Wilber RG, Davy DT. A kinematic study of the cervical spine before and after segmental arthrodesis. Spine (Phila Pa 1976) 1998;23:1649-56.

36. Nagata H, Schendel MJ, Transfeldt EE, Lewis JL. The effects of immobilization of long segments of the spine on the adjacent and distal facet force and lumbosacral motion. Spine (Phila Pa 1976) 1993;18:24719.

37. Gore DR, Sepic SB. Anterior discectomy and fusion for painful cervical disc disease. A report of $50 \mathrm{pa}-$ tients with an average follow-up of 21 years. Spine (Phila Pa 1976) 1998;23:2047-51.

38. Boden SD, McCowin PR, Davis DO, Dina TS, Mark AS, Wiesel S. Abnormal magnetic-resonance scans of the cervical spine in asymptomatic subjects: a prospective investigation. J Bone Joint Surg Am 1990; 72:1178-84.

39. Matsumoto M, Fujimura Y, Suzuki N, et al. MRI of cervical intervertebral discs in asymptomatic subjects. J Bone Joint Surg Br 1998;80:19-24.

40. Lunsford LD, Bissonette DJ, Jannetta PJ, Sheptak PE, Zorub DS. Anterior surgery for cervical disc disease. Part 1: Treatment of lateral cervical disc herniation in 253 cases. J Neurosurg 1980;53:1-11.

41. Henderson CM, Hennessy RG, Shuey HM Jr, Shackelford EG. Posterior-lateral foraminotomy as an exclusive operative technique for cervical radiculopathy: a review of 846 consecutively operated cases. Neurosurgery 1983;13:504-12.

42. Herkowitz HN, Kurz LT, Overholt DP. Surgical management of cervical soft disc herniation: a comparison between the anterior and posterior approach. Spine (Phila Pa 1976) 1990;15:1026-30.

43. Etebar S, Cahill DW. Risk factors for adjacentsegment failure following lumbar fixation with rigid instrumentation for degenerative instability. J Neurosurg 1999;90(2 Suppl):163-9.

44. Bastian L, Lange U, Knop C, Tusch G, Blauth M. Evaluation of the mobility of adjacent segments after posterior thoracolumbar fixation: a biomechanical study. Eur Spine J 2001;10:295-300.

45. Shono Y, Kaneda K, Abumi K, McAfee PC, Cunningham BW. Stability of posterior spinal instrumentation and its effects on adjacent motion segments in the lumbosacral spine. Spine (Phila Pa 1976) 1998;23: 1550-8. 
46. Weinhoffer SL, Guyer RD, Herbert M, Griffith SL. Intradiscal pressure measurements above an instrumented fusion: a cadaveric study. Spine (Phila $\mathrm{Pa}$ 1976) 1995;20:526-31.

47. Ahn DK, Lee S, Jeong KW, Park JS, Cha SK, Park HS. Adjacent segment failure after lumbar spine fusion: controlled study for risk factors. J Korean Orthop Assoc 2005;40:203-8.

48. Ghiselli G, Wang JC, Bhatia NN, Hsu WK, Dawson EG. Adjacent segment degeneration in the lumbar spine. J Bone Joint Surg Am 2004;86:1497-503.

49. Nunley PD, Jawahar A, Kerr EJ 3rd, et al. Factors affecting the incidence of symptomatic adjacent-level disease in cervical spine after total disc arthroplasty: 2 - to 4-year follow-up of 3 prospective randomized trials. Spine (Phila Pa 1976) 2012;37:445-51.

50. Nassr A, Lee JY, Bashir RS, et al. Does incorrect level needle localization during anterior cervical discectomy and fusion lead to accelerated disc degeneration? Spine (Phila Pa 1976) 2009;34:189-92.

51. Goffin J, Geusens E, Vantomme N, et al. Long-term follow-up after interbody fusion of the cervical spine. J Spinal Disord Tech 2004;17:79-85.

52. Chung JY, Kim SK, Jung ST, Lee KB. Clinical adjacent-segment pathology after anterior cervical discectomy and fusion: results after a minimum of 10year follow-up. Spine J 2014;14:2290-8.

53. Gore DR, Sepic SB. Anterior cervical fusion for degenerated or protruded discs. A review of one hundred forty-six patients. Spine (Phila Pa 1976) 1984;9: 667-71.

54. Kawakami M, Tamaki T, Yoshida M, Hayashi N, Ando M, Yamada H. Axial symptoms and cervical alignments after cervical anterior spinal fusion for patients with cervical myelopathy. J Spinal Disord 1999;12:506.

55. Teramoto T, Ohmori K, Takatsu T, Inoue H, Ishida Y, Suzuki K. Long-term results of the anterior cervical spondylodesis. Neurosurgery 1994;35:64-8.

56. Komura S, Miyamoto K, Hosoe H, Iinuma N, Shimizu K. Lower incidence of adjacent segment degeneration after anterior cervical fusion found with those fusing C5-6 and C6-7 than those leaving C5-6 or C6-7 as an adjacent level. J Spinal Disord Tech 2012;25:23-9.

57. Song KJ, Choi BW, Jeon TS, Lee KB, Chang H. Adjacent segment degenerative disease: is it due to disease progression or a fusion-associated phenomenon? Comparison between segments adjacent to the fused and non-fused segments. Eur Spine J 2011;20:1940-5.

58. Marotta N, Landi A, Tarantino R, Mancarella C, Ruggeri A, Delfini R. Five-year outcome of stand-alone fusion using carbon cages in cervical disc arthrosis. Eur Spine J 2011;20 Suppl 1:S8-12.

59. Bolesta MJ, Rechtine GR 2nd, Chrin AM. One- and two-level anterior cervical discectomy and fusion: the effect of plate fixation. Spine J 2002;2:197-203.

60. Katsuura A, Hukuda S, Saruhashi Y, Mori K. Kyphotic malalignment after anterior cervical fusion is one of the factors promoting the degenerative process in adjacent intervertebral levels. Eur Spine J 2001;10: 320-4.

61. Wu JC, Liu L, Wen-Cheng H, Chen YC, et al. The incidence of adjacent segment disease requiring surgery after anterior cervical diskectomy and fusion: estimation using an 11-year comprehensive nationwide database in Taiwan. Neurosurgery 2012;70:594601.

62. Williams JL, Allen MB Jr, Harkess JW. Late results of cervical discectomy and interbody fusion: some factors influencing the results. J Bone Joint Surg Am 1968;50:277-86.

63. Lee JC, Lee SH, Peters C, Riew KD. Risk-factor analysis of adjacent-segment pathology requiring surgery following anterior, posterior, fusion, and nonfusion cervical spine operations: survivorship analysis of 1358 patients. J Bone Joint Surg Am 2014;96:1761-7.

64. Park JB, Cho YS, Riew KD. Development of adjacentlevel ossification in patients with an anterior cervical plate. J Bone Joint Surg Am 2005;87:558-63.

65. Park JB, Watthanaaphisit T, Riew KD. Timing of development of adjacent-level ossification after anterior cervical arthrodesis with plates. Spine J 2007;7:633-6.

66. Koller H, Reynolds J, Zenner J, et al. Mid- to longterm outcome of instrumented anterior cervical fusion for subaxial injuries. Eur Spine J 2009;18:630-53.

67. Park Y, Maeda T, Cho W, Riew KD. Comparison of anterior cervical fusion after two-level discectomy or single-level corpectomy: sagittal alignment, cervical lordosis, graft collapse, and adjacent-level ossification. Spine J 2010;10:193-9.

68. Yang JY, Song HS, Lee M, Bohlman HH, Riew KD. Adjacent level ossification development after anterior cervical fusion without plate fixation. Spine (Phila Pa 
1976) 2009;34:30-3.

69. Kim HJ, Kelly MP, Ely CG, Dettori JR, Riew KD. The risk of adjacent-level ossification development after surgery in the cervical spine: are there factors that affect the risk? A systematic review. Spine (Phila Pa 1976) 2012;37(22 Suppl):S65-74.

70. Yang H, Lu X, He H, et al. Longer plate-to-disc distance prevents adjacent-level ossification development but does not influence adjacent-segment degeneration. Spine (Phila Pa 1976) 2015;40:E388-93.

71. Song KJ, Lee KB, Yim JH. Does preoperative cervical sagittal alignment and range of motion affect adjacent segment degeneration after anterior arthrodesis in degenerative cervical spinal disorders?: midterm follow up study. J Korean Soc Spine Surg 2014;21:1-7.

72. Faldini C, Miscione MT, Acri F, et al. Single level cervical fusion by an anterior approach using autologous bone graft influences the adjacent levels degenera- tive changes: clinical and radiographic results at 10year minimum follow-up. Eur Spine J 2012;21 Suppl 1:S90-3.

73. Faldini C, Pagkrati S, Leonetti D, Miscione MT, Giannini S. Sagittal segmental alignment as predictor of adjacent-level degeneration after a cloward procedure. Clin Orthop Relat Res 2011;469:674-81.

74. Oda I, Cunningham BW, Buckley RA, et al. Does spinal kyphotic deformity influence the biomechanical characteristics of the adjacent motion segments? An in vivo animal model. Spine (Phila Pa 1976) 1999;24: 2139-46.

75. Park MS, Kelly MP, Lee DH, Min WK, Rahman RK, Riew KD. Sagittal alignment as a predictor of clinical adjacent segment pathology requiring surgery after anterior cervical arthrodesis. Spine J 2014;14:122834. 